\title{
NOTAS SOBRE O ESQUEMATISMO NA CRÍTICA DA RAZÃO PURA DE KANT ${ }^{1}$
}

Ubirajara Rancan de Azevedo MARQUES ${ }^{2}$

- RESUMO: Trata-se de uma abordagem introdutória à doutrina do esquematismo, segundo o contexto de seu surgimento na Crítica da Razão Pura.

- PALAVRAS-CHAVE: Esquema; esquematismo; esquematismo transcendental; imagem.

Há textos de Filosofia cuja estranheza, às vezes maximizada, confere-lhes notoriedade perversa, influindo na exata compreensão de problemas e soluções propostos. Esse parece ser, de modo geral, o tom freqüente com que se aborda o capítulo do esquematismo na Crítica da Razão Pura. Inúmeras têm sido as referências - nem sempre felizes - às dificuldades que encerra a Schematismuslehre. Observe-se, contudo, que o próprio Kant (Ak., v.XVIII, n.6359, p.686, 1.6-16) é quem primeiro reconhece a questão:

através da determinação transcendental do tempo (posto que ela é homogênea com os fenômenos e com as categorias), a aplicação das categorias aos fenômenos é mediada e tornada possivel. A dificuldade parece ser - posto que a própria determinação transcendental do tempo é já um produto da apercepção em relação à forma da intuição, e, pois, suscita também a própria questão - como é possivel a aplicação da categoria à forma da intuição, visto que categoria e forma da intuição são heterogêneas. De modo geral, o esquematismo é um dos pontos mais dificeis. - Mesmo o Sr. Beck não consegue haver-se por lá. Tomo este capitulo por um dos mais importantes.

Da mesma forma, nos Prolegômenos afirma-se terem sido

1 Oartigo que se vai ler é a reelaboração do terceiro e último capítulo de minha Dissertação de Mestrado, apresentada em agosto de 1990, na Universidade de São Paulo. Na ocasião, a Banca Examinadora foi composta pelos Professores Doutores: Carlos Alberto Ribeiro de Moura, Marcos Lutz Müller e Gérard Lebrun (Orientador), aos quais novamente agradeço, isentando-os, é claro, das muitas imperfeições ainda restantes no texto.

2 Professor Assistente junto ao Departamento de Filosofia - Faculdade de Filosofia e Ciências - UNESP - 17525-900

- Campus de Marília. 
necessárias duas investigações importantes, até completamente indispensáveis, embora extremamente áridas, que foram feitas na Crítica, p.137 etc., e p.235 etc., por cuja primeira foi mostrado que os sentidos não fornecem os conceitos puros do entendimento in concreto, mas apenas o esquema para o uso dos mesmos, e o objeto a ele conforme é encontrado apenas na experiência (como o produto do entendimento a partir dos materiais da sensibilidade). (Idem, v.4, p.316, l.6-12)

\section{Mas o texto dos Prolegômenos vincula ainda o esquematismo à temática central da Crítica:}

Como... a proposição de que juizos de experiência devem conter necessidade na síntese das percepções harmoniza-se com minha proposição ... [a saber,] que a experiência como conhecimento a posteriori só pode dar juizos contingentes? Quando digo: a experiência ensina-me algo, considero sempre apenas a percepção que reside nela, por exemplo, que o calor segue sempre à luz do sol na pedra, e, portanto, a proposição de experiência é nessa medida sempre contingente; que esse aquecimento resulte necessariamente da luz do sol, [tal] está em verdade contido nos juizos de experiência (em virtude do conceito de causa), mas isso eu não aprendo por experiência, mas, ao contrário, a experiência é primeiramente produzida através dessa adjunção do conceito do entendimento (de causa) à percepção. Como a percepção chega a essa adjunção, sobre isso deve ser revista a Crítica na seção do "Juizo transcendental", p.137 e seguintes. (Idem, v.IV, p.305, 1. $23-5)^{3}$

Não obstante tais considerações, opinou-se, por exemplo, que:

The chapter on schematism probably presents more difficulty to the uncommited but sympathetic reader than any other part of the Critique of Pure Reason. Not only are the details of the argument highly obscure ...: it is hard to say in plain terms what general point or points Kant is seeking to establish. (E a respeito do esquema como "o terceiro" (Das Dritte) que "medeia" (vermittelt) entre a intuição e o conceito:] "It is hard not to think of this as an artificial solution, conceived in a crude pictorial manner ...". (Walsh, 1957-1958, p.95) ${ }^{4}$

Também Vleeschauwer (1976, v.I, p.25), referindo-se a uma expressão tornada famosa no capítulo do esquematismo, faz dele uma espécie de modelo da obscuridade:

Kant, en effet, vivait à une époque où le langage technique de la philosophie allemande n'avait pas atteint la perfection d'aujourd'hui, et en un lieu peu approprié pour pouvoir fournir à la pensée un vocabulaire claire et précis. Cette maladresse dans l'expression devait être en outre au service d'une pensée peu comune et d'un programme compliqué à plaisir. Il ne s'agit de rien moins que d'un art caché dans les profondeurs de l'âme, comme s'exprimait Kant lui-même au sujet du schématisme.

Inúmeras, de resto, as passagens em que o mesmo comentador, já a respeito do próprio esquematismo, emite pareceres semelhantes:

3 Cf. Kant, Ak., v. XX, p.274, 1.6-14; p.279-80, 1.25/02; p.332, 1.30-6. (Acerca da tradução de Urteilskraft por juízo, cf. Kant, Ak., v.XVI, n.1861, p.139, 1.14-25: "Juizo (Urtheilskraft), judgement, bom senso (gesunder Verstand) são uma só coisa e a capacidade intelectual (Verstandesfähigkeit) na aplicação."]

4 Cf. Dahlstrom, 1984, p.38-41. 
On sait que le schématisme destiné à parachever la théorie incomplètement élaborée dans la déduction au sujet de ce problème ["l'unité sensitivo-intelectuelle dans la connaissance"], se débat dans des obscuntés si denses qu'il est vain d'en attendre quelque résultat positif. (Vleeschauwer, 1976, v.II, p.398); La subsomption est un acte intellectuel que nous aimerions à voir éclairci et désarticulé surtout parce que le schématisme s'entoure dans la Critique d'obscurités telles que l'oeil le mieux exercé dans le dédale kantien ne parvient pas à les dissiper.(Idem, p.492); [trata-se de um capítulo] à peu près inintelligible. (Idem, v.III, p.184); Le schématisme, c'est-à-dire la fonction d'exposer la catégorie ou la Zusammensetzung dans l'intuition correspondante, achève la déduction de l'objectivité de la connaissance. Pas plus que dans la Critique, nous ne pouvons considérer le paragraphe que les Fortschritte y consacrent comme l'explication satisfaisante de cet art caché dans les profondeurs de l'esprit. (Idem, p.474-5)

Deleuze (1976, p.32), ${ }^{5}$ igualmente, observa: "Que relações espaço-temporais possam ser adequadas a relações conceituais (apesar de sua diferença de natureza) consiste, segundo Kant, em um profundo mistério e uma arte oculta".

Um sem-número de outras citações poderia ser arrolado (cf., por exemplo, Moreau, 1988, p.286-92; Belaval, 1982, p.27-8). ${ }^{6}$

Mais razoável, talvez - e, decerto, prudente -, é dizer, com Lehmann (1969, p.188-9), que o esquematismo dos conceitos puros do entendimento é um "capítulo espinhoso da primeira edição, que infelizmente foi mantido inalterado na segunda".

Mas a própria Crítica contém várias e importantes referências ao esquematismo (Martin, 1967) ${ }^{7}$ - todas concordes com o capítulo em que a doutrina é exposta -, contribuindo para a sua inteligibilidade. Por exemplo:

5 Trata-se de uma interpretação posteriormente reordenada e publicada em forma de artigo (cf. Philonenko, 1982, p. 11-32). Mas, ainda em vida, Kant receberia as primeiras críticas à Schematismuslehre; (cf. Zwanziger apud Mellin, 1797-1804, v.V, n.1, p.182, nota; Brastberger apud Mellin, 1797-1804, v.v, n.1, p. 183, nota; Herder, 1799, primeira parte, p.269-74).

6 Moreau parece desconhecer as considerações de Philonenko sobre o tema (não o cita uma só vez), diante das quais, no entanto, se as conhecesse, estaria em débito. Watson (1976, p.172) também fazia alusão a Berkeley, nesse mesmo ponto

7 Martin, 1967, p.241

"Schema

134271350113523135241352513528

$13537136021360613611 \quad 1362313627$

$1362813637 \quad 13705137241373013801$

138051380913814138151381713819

138231382613835139111391413923

139241393514428150071612016128

161352030920807229312811528117

374354392343934440024400344008

440104401244301443104450844521

448054492544932450124503145033

458084591546932472115391253914

$539255393054016^{\prime \prime}$

"Schematismus

13322133311352413618138 30".

(Os três primeiros algarismos referem-se à página, os dois últimos à linha, no v.III da "Edição da Academia". Os algarismos em itálico salientam as principais referências ao esquema e ao esquematismo.) 
O pensamento é a ação de referir a intuição dada a um objeto. Se o modo dessa intuição não é dado de maneira alguma, então o objeto é meramente transcendental e o conceito do entendimento não tem nenhum outro uso senão o transcendental, a saber, a unidade do pensamento de um múltiplo em geral. Ora, através de uma categoria pura - na qual se abstrai de toda condição da intuição sensivel, como da única possivel a nós - nenhum objeto, pois, é determinado, mas apenas expresso o pensamento de um objeto em geral, segundo diferentes modos. Ora, pertence ainda ao uso de um conceito uma função do juizo (Urteilskraft), pela qual um objeto é subsumido a ele, por conseguinte, a condição ao menos formal sob a qual algo pode ser dado na intuição. Se falta essa condição do juizo (esquema), suprime-se toda subsunção, pois nada é dado que possa subsumir-se ao conceito. (Kant, KrV., A, p.257, B p.304) ${ }^{8}$

De resto, não obstante a dificuldade e aridez do capítulo do esquematismo, note-se que Kant (Ak., v.XXIII) ${ }^{9}$ não lhe apôs nenhuma nova explicação ou qualquer emenda de importância.

Temos então, segundo o testemunho de Kant (KrV., A, p.136, B, p.175), que o "esquematismo do entendimento puro" trata da "condição sensivel unicamente sob a qual conceitos puros do entendimento podem ser usados". Investigação importante, completamente indispensável (embora extremamente árida) (Cf. Kant, Ak., v.IV, p.316, 1. 6-12), vindo a ser dos "mais importantes" capítulos da Crítica da Razão Pura (Idem, v.XVIII, n.6359, p.686, 1.6-16). Mas por que a mesma doutrina permanece ainda supostamente incompreensível? Por que essas meras dez (A 137-47) ou 11 (B 176-87) páginas devem sua reputação sobretudo à presumida ininteligibilidade? Compreende-se - dado o papel que aparentemente lhe atribui Kant - que, ou o mistério a envolver o esquematismo espraia-se por grande parte da obra, ou que, nem a eventual clareza desta, nem a provável obscuridade dele têm algo de fundamental em comum, permanecendo o mesmo um aditamento artificial, e, portanto, suprimível. Dentre ambas as posturas, decerto radicais, algo de comum emerge, e com a força suplementar que lhe confere a chancela do autor: a dificuldade do texto. Nada além de um "capítulo espinhoso"... Mas é no restante dessa observação de Lehmann (1969, p.188-9) que se pode descobrir um dos entraves para a compreensão do esquematismo, já que, "infelizmente", ele "foi mantido inalterado na segunda" edição da Crítica. Ora, o esquema "é em si mesmo sempre só um produto da imaginação" (Kant, KrV., A, p.140, B, p.179). ${ }^{10}$ Assim - embora Lehmann não o afirme -, a infelicidade acerca da inalteração do capítulo do esquematismo em 1787 pode, em parte, decorrer do fato de a imaginação não ter agora as mesmas atribuições que em 1781 - ou, se se quiser, de não as ter com igual autonomia; mas, de outro lado, pode advir também de a própria

8 Cf. Kant, KrV, A, p.180-1, B, p.223-4; A, p.664-6, B, p.692-4; A, p.714, B, p.742; A, p.717-8, B, p.745-6; Kant, Ak, v.VIII, p.133, 1. 1-13.

9 Kant, Ak., v.XXIII ("Selbständige Reflexionen im Handexemplar" - Nr.: LIII; LIV; LV; LVI; LVII; LX); p.27; 1.6-30; idem \{"Textemendationen" - (A 139 (IV 100 10-11); A 142 (IV 101 35)]\}; p. 46; I. 13-6.

10 Cf. as judiciosas observações de Cohen (1920, p.72), acerca do esquema como produto, as quais, anos depois, seriam retomadas pelo Philonenko (1969, v.I, p.182-5). 
mecânica do esquematismo já estar presente na nova dedução, ao longo do § $24 .{ }^{11}$ Decerto que ambas as possibilidades confluem; todavia, nem por isso são sinônimas. Na verdade, atribuir parte da dificuldade de compreensão do esquematismo em 1787 às alterações sofridas pela imaginação é, sobretudo, estranhar a manutenção da letra de 1781; mas, reconhecê-lo nas formulações do § 24 é, bem mais, surpreender-se com a apresentação - posterior - da própria doutrina do esquematismo, como se, não havendo referência anterior, se tratasse de uma exposição original. Uma coisa é, em 1781, compreender que o esquema, "produto da imaginação", perfaz a "determinação transcendental do tempo" (Idem, A, p.138-9, B, p.177-8); outra, em 1787, reler que assim se dá, quando se disse antes que uma "intuição determinada" só é possível "pela consciência da determinação do mesmo ["o sentido interno"] através da ação transcendental da imaginação (influência sintética do entendimento sobre o sentido interno)" (Idem, B, p.154).

Há, com respeito às funções da imaginação, textos de uma divergência à primeira vista gritante. Com efeito, teríamos por que lamentar a manutenção dessa famosa passagem do § 10 da Crítica:

A sintese em geral, como futuramente veremos, é o mero efeito da imaginação, uma função da alma, cega mas indispensável, sem a qual de modo algum teriamos um conhecimento, porém da qual apenas raramente somos conscientes. (Idem, A, p.78, B, p.103) (2 $^{12}$ wie wir künftig sehen werden... [Mas o que se vê em 1787 é algo de certo modo distinto] "a ligação coniunctio de um múltiplo em geral não pode nunca nos advir dos sentidos, e, portanto, também não pode estar ao mesmo tempo contida na forma pura da intuição sensivel, pois é um ato da espontaneidade da capacidade de representação, e, visto que se tem de nomear a esta de entendimento, em diferença à sensibilidade, toda ligação - possamos ou não ser conscientes dela, seja uma ligação do múltiplo da intuição ou de vários conceitos, e, no primeiro caso, da intuição sensível ou não sensível - é uma ação do entendimento que designaremos com o nome geral de sintese, a fim de, com isso, ao mesmo tempo chamar a atenção para o fato de que nada podemos representar-nos como ligado no objeto sem o termos nós mesmos ligado antes, e, dentre todas as representações, a ligação é a única que não pode ser dada por objetos, mas cumprida apenas pelo próprio sujeito, porque é um ato da sua espontaneidade." (Idem, B, p.129-30) ${ }^{13}$

11 Cf. Vleeschauwer, 1976, v.3, p.180-221; Prichard, 1976, p.246-7; Deleuze, 1976, p.37-43; Rocca, 1989, p.129-31; Wolff, 1973, p.44, 206 ss.

12 Em seu exemplar da Crítica, Kant escreveria, em lugar de "uma função da alma", "uma função do entendimento" [Cf. Ak., XXIII, ("Textemendationem"), p.45, 1. 29-31].

13 Em contrapartida, cf.: KrV, A, p.123: "A imaginação é pois também uma faculdade de uma síntese a priori, em razão do que lhe damos o nome de imaginação produtiva; e, à medida que, em referência a todo o múltiplo do fenômeno, ela nada mais tem em vista senão a unidade necessária na síntese do mesmo, esta pode ser nomeada a função transcendental da imaginação. É pois em verdade estranho, contudo óbvio do até agora (vistol, que mesmo a afinidade dos fenômenos, com ela a associação e através desta por fim a reprodução segundo leis, conseqüentemente a própria experiência, só por meio dessa função transcendental da imaginação seja possível: pois que sem ela nenhuns conceitos de objetos confluiriam para a experiência (in einer Erfahrung zusammenfliessen würden)". Observe-se o dado de que "sem ela nenhuns conceitos de objetos confluiriam para a experiência" - o que de imediato faz pensar no esquematismo. Cf. também o comentário de Beck, 1793, p.25-6: "O segundo 
Mas, qualquer que tenha sido a razão da mudança de estatuto da Einbildungskraft em 1787, parece-me que suas funções, no principal, permaneceram intocadas, mesmo se as considerarmos agora um simples poder subordinado ao entendimento. "Imaginação" ou "entendimento", tal no limite é secundário, indicando-o, a meu ver, as palavras de Kant (Idem, B, p.162, nota): “... a síntese da apreensão, que é empírica, deve necessariamente conformar-se à síntese da apercepção, que é intelectual e está inteiramente contida a priori na categoria. É uma e a mesma espontaneidade (Es ist eine und dieselbe Spontaneität) que, lá, sob o nome de imaginação, aqui, de entendimento, introduz a ligação no múltiplo da intuição". Importará frisar a mesmidade da Spontaneität ou ressalvar que ela terá perdido o que mais a distinguia - a saber, a oposição à "receptividade" -, na medida em que a imaginação, que, como sensivel era também receptiva, exerce agora uma atividade espontânea? Mas a imaginação continuará tão receptiva e espontânea quanto antes (Idem, A, p.124, B, p.164). Mais que enfatizar a mesmidade da Spontaneität valerá notar a parcimônia da diferença entre "entendimento" e "imaginação", ou o hibridismo desta última, tanto mais forte quanto mais fortemente se oponham Spontaneität e Rezeptivität. Ora, no capítulo do esquematismo a imaginação será primeiramente nomeada só ao início do sexto parágrafo (ou à terceira das dez ou onze páginas que o texto contém), perfazendo a caracterização do esquema como elemento mediador: "O esquema é em si mesmo sempre só um produto da imaginação" (Idem, A, p.143, B, p.179). Mas tudo que precede $o$ anúncio dessa paternidade - mesmo fora do capítulo em questão - faz antecipar a genealogia do esquema. Decerto que os pormenores de algo como o esquematismo - a própria denominação que tanto faz elocubrar o intérprete (Vleeschauwer, 1976, v.I, p.301-2, nota; Paton, 1970, v.II, p.18, nota; Daval, 1951, p.5-8) - não poderiam ser previstos; mas o caráter de sua função e a indispensabilidade (Unentbehrlichkeit) no sistema - e não por um capricho arquitetônico -, tais são aspectos que o estudo da "Analítica" facilmente traz à luz em sua coerência e propósito.

Verdade que a Crítica não prima pela clareza expositiva - mas, de resto, seu primado é outro (Kant, KrV., p.XVII-XIX; Ak., v.IV, p.262, 1.26-35). Contudo, ela dispõe de um plano, uma "idéia do todo" (Idee des Ganzen) (Kant, KrV, A, p.64, B, p.89), uma "unidade sistemática" (Idem, A, p.832-5, B, p.860-3). Desse modo, mas sem ser a título de mero efeito dela, o esquematismo está perfeitamente ajustado à "arquitetônica" crítica, bem como, ademais, à própria arquitetura, ao feitio que a realização da "idéia" assume nas etapas do discurso. Mas nem por isso ele se resume a uma espécie de adorno: sua presença não está a serviço de um estilo, mas da consecução de um "princípio".

[elemento] exigido para um conhecimento é a sintese. Esta consiste na ação de acrescentar diversas representaçōes umas às outras, por onde se torna possivel compreendê-las todas numa consciência. Esta [síntese] é já uma propriedade da espontaneidade, e portanto do entendimento, mas não perfaz ainda um conhecimento." onde, apesar de o texto de 1787 (sobre o qual é feito o comentário) repetir o de 1781, a "síntese" já é tomada como função do entendimento. 
O pressuposto que fundamenta, quer a "Estética", quer a "Analítica", é: "na medida em que deve haver razão nelas [nas ciências], algo aí deve poder ser conhecido a priori" (Idem, B, p.IX). ${ }^{14}$ O princípio, portanto: "nós só conhecemos a priori das coisas o que nós próprios colocamos nelas" (Idem, B, p.XVIII); e, transcrito nos termos da "dedução transcendental": "nada podemos representar-nos como ligado no objeto sem o termos nós mesmos ligado antes" (Idem, B, p.130). ${ }^{15}$ Ora, é precisamente a um tal "princípio", aos problemas que sua realização suscita que se refere a "tão natural e relevante questão" do capítulo do esquematismo: "Como é... possível a subsunção das últimas [das "intuições"] aos primeiros [aos "conceitos puros do entendimento"], por conseguinte, a aplicação da categoria a fenômenos ...?" (Idem, A, p.137, B, p.176).

De uma certa maneira, o esquema, na "lógica transcendental", ocupa a função do "termo médio", na "lógica geral". ${ }^{16}$ No silogismo:

TODOS OS HOMENS SÃO MORTAIS;

CAIO É HOMEM;

LOGO, CAIO É MORTAL (Kant, Ak., v.IX, p. 102, 1.21-3), ${ }^{17}$ o termo médio, "homem", é o que permite a subsunção da premissa menor ("CAIO É HOMEM") à maior ("TODOS OS HOMENS SÃO MORTAIS"), e assim a conclusão. O que portanto faculta o conhecimento do que quer que seja e se refira aos objetos da experiência, isto é, a subsunção das intuições aos conceitos puros do entendimento (e, por conseguinte, o conhecimento em sentido próprio), tal é o esquema - o intermediário, o elemento da intersecção. O próprio Kant concebeu assim o esquematismo, isto é, o "procedimento" (Verfahren) do entendimento com os esquemas (KrV., A, p.140, B, p.179): "O esquematismo dos conceitos do entendimento segundo a forma de um silogismo (Vemunftschluss): 1. A premissa maior (Obersatz); 2. A subsunção da premissa menor (Untersatz) e 3. O termo (Schluss) ou a conclusão (Conclusion) a favor da experiência em geral. [Tal é] a exigência para a possibilidade da experiência, [exigência] que apresenta, segundo a forma, o sistema das percepções a priori, e contém, da intuição às analogias da experiência, através das antecipações da percepção, o empírico da representação na completa determinação dela. ${ }^{18}$

Verdade, porém, que a simetria desse quadro é em parte constrangedora, levando-nos a crer em intuições e categorias já dadas por si mesmas como tais - 0 que, no entanto, não é propriamente exato. A rigor, pois, não ocorreria uma simples subsunção das intuições às categorias, mas uma verdadeira fusão de disposições: umas, provindo dos objetos afetantes; outras, da auto-afecção do eu por ocasião dos primeiros. Somente com uma tal fusão poderia dar-se, de um lado, o conceito, de

14 Cf. Kant, Ak., v.XVIII, n.5640, p.279, 1. 2: "Uma razão que fosse determinada sensivelmente não seria razão." 15 Pode-se falar ainda do mesmo princípio, transcrito nos termos da Schematismuslehre: cf. Kaulbach, 1960, p.466:

"Só o que a razão descreveu prescrevendo ela pode conhecer a priori."

16 Cf. Philonenko, 1982, p.16; Winterbourne, 1981, p.36, 38; Paton, 1970, v.II, p.65-8.

17 Cf. Kant, KrV., A, p.321-2, B, p. 378.

18 Kant, Ak., v.XXII ("XI. Conv., V. Bogen, 4. Seite”), p.494, l. 17-24. 
outro, a intuição. Nesse sentido, não obstante o paralelismo com o termo médio, tampouco o esquema já se encontraria como que de antemão acabado, carecendo assim - e sobretudo ele! - da própria fusão entre o sensível e o intelectual. Mas de que modo conciliar essa exigência com a obrigação que ele tem de promover a "concordância" (Übereinstimmung) entre a categoria e a intuição? Trata-se de propostas aparentemente enviezadas!

Mas a própria facultas imaginandi parecerá estranha conjugando o que a Crítica tão ciosamente reparte. A intermediação que o esquema realiza será, pois, oculta (verborgen), em razão do hibridismo de que desfruta a imaginação. De fato, como conciliar a impositiva distinção entre o "espontâneo" e o "receptivo" perante a não menos impositiva tarefa de reuni-los? (Belaval, 1982, p.32) Compreender a "Analítica" é dissipar esse nó górdio.

Parece-me claro que o problema de um ajustamento entre partes opostas devendo compor-se - tal é o mote do esquematismo - fatalmente reavivará, no conjunto das filosofias da representação, esta ou aquela faceta de um mesmo cenário. Nesse sentido, a solução da Schematismuslehre pode não ter sido alcançada ou satisfazer, mas, do ponto de vista da história da filosofia é a retomada de um esforço que retrocede a Platão. ${ }^{19}$ Porém, o que realmente constitui a marca do traço kantiano é o propósito de recolocar a "tão natural e relevante questão", em que naturalidade e relevância dão, agora, contorno ao "destino" da "razão humana", trilhado no "campo de batalha" dos "infindáveis conflitos" da "metafísica" (Kant, KrV., A, p.VII-VIII).

Todavia, o esquematismo não partirá de uma questão metafísica, mas reelaborará uma questão da Metafísica, à exata medida que o criticismo reelabora a filosofia da representação, pois a Vorstellung é um produto da subjetividade transcendental com base em objetos indeterminados.

A tonalidade crítica dessa questão.apontará os limites e as condições de uma eventual resposta. Não se trata, aqui também, de propriamente responder, mas apenas assentar a jurisprudência que prefixe um "domínio" (Gebiet). Porém, se a "tão natural e relevante questão" assemelha-se à que o problema do conhecimento comporta na filosofia moderna, ela não se manifesta apenas no referido capítulo da "Analítica transcendental", sendo o próprio pano de fundo da noção de Erkenntnis que atravessa a obra.

Afirmando que "a definição nominal da verdade, a saber, que ela é a concordância (Übereinstimmung) do conhecimento com seu objeto, é aqui concedida e pressuposta" (Idem, A, p.58, B, p.82), Kant não só retoma a velha fórmula, como herda a problemática que inseparavelmente a segue. Assim, relativamente à "Analítica transcendental" ou "lógica da verdade", "nenhum conhecimento pode contradizê-la sem que ao mesmo tempo perca todo conteúdo, isto é, toda referência a qualquer

19 Cf. Rotenstreich, 1956, p.22-9; Pippin, 1976, p.159; Moreau, 1988, p.291-2; Belaval, 1982, p.30-1. 
objeto, por conseguinte, toda verdade" (Idem, A, p.62-3, B, p.87). Destarte, a filosofia transcendental "tem... de expor as condições sob as quais os objetos podem ser dados em concordância (Übereinstimmung) com aqueles conceitos los conceitos puros do entendimento]" (Idem, A, p.136, B, p.175). Ora, vê-se assim que a "aplicação" das categorias às intuições ou a "subsunção" dos fenômenos aos conceitos ocupa-se com a possibilidade da "concordância" entre os "objetos" e os "conceitos puros do entendimento", isto é , entre o que afeta a sensibilidade e o que pensa este dado. Eis o problema combatido pelo esquema. Mas não há como saber se cada objeto e seu conhecimento concordam materialmente entre si; não pode haver critério para cada concordância material buscada. Todavia, a lógica transcendental responde pelo conteúdo do objeto, segundo as condições subjetivas da representação de sua matéria. No critério formal da lógica, a concordância é estabelecida na conclusão mediante a subsunção da menor à maior pelo termo médio. No critério da concordância entre conhecimento e objeto, a concordância é estabelecida no juízo mediante a subsunção da intuição ao conceito (ou a aplicação da categoria ao fenômeno) pelo esquema transcendental. Mas a concordância só é possível aplicando-se a esse raciocínio o princípio que norteia a filosofia crítica: "nós só conhecemos a priori das coisas o que nós próprios colocamos nelas". Portanto, a concordância se dá só à medida que se forjam as condições de recepção e enformação da matéria, isto é, quando se fundem as disposições sensível e intelectual.

Parte da dificuldade da dedução, reiteradamente lembrada por Kant, deveu-se à questão do alcance das categorias, de um suposto fundamento do seu "uso transcendental" (Idem, B, p.146-9). A dedução fixou a prova da inutilidade dessa esperança natural, e o esquematismo deverá contraprová-la pelo coroamento da única positividade cabível no uso das categorias, isto é, através da realização do conhecimento fenomênico - donde, aliás, a procedência na lembrança dos resultados daquela:

após o que foi mostrado na dedução das categorias, oxalá ninguém esteja em dúvida para decidir-se sobre a questão se esses conceitos puros do entendimento são de uso meramente empírico ou também de uso transcendental; se como condições de uma experiência possivel eles se referem a priori unicamente a fenômenos, ou se como condições da possibilidade das coisas em geral podem ser estendidos a objetos em si mesmos (sem qualquer restrição a nossa sensibilidade). (Idem, A, p.139, B, p.178) [Da mesma forma, Kant ainda escreveria] "É uma questão muito importante [saber] se as categorias são meramente de uso empírico ou também transcendental. - À esquematística (Zur Schematistik)." (Kant, Ak., v.XVIII, n.5636, p.268, 1.27-8)

Ora, a "determinação transcendental do tempo", isto é, a ligação categorial do múltiplo do sentido interno pelas categorias - tal é a primeira denominação que o esquema recebe (Kant, KrV., A, p.139, B, p.178) - não se dá simplesmente entre as categorias e o múltiplo puro, ambos de antemão constituídos. É no processo de elaboração do objeto de conhecimento que eles se perfazem, sem que, tampouco, para isso intervenha um "terceiro", então supostamente pré-formado, a fim de 
possibilitar o acordo. O próprio esquema não poderá ser originariamente visto como o catalizador da aplicação das categorias aos fenômenos, mas sim como o resultado da fusão de disposições antagônicas, à medida que a Anwendung é feita pelo entendimento como imaginação transcendental.

Da maneira como é exposta a Crítica, tem-se por vezes a impressão de um quebra-cabeça. A possibilidade do conhecimento não suporta uma dualidade elementar. Para que ele ocorra é preciso um entendimento imaginativo, uma consciência, por assim dizer, talentosa. Surgiria, pois, um "terceiro" para operar a tão fundamental e insuportável distinção entre o sinnlich e o verständlich? O risco de interpretar-se o esquema como um artifício conceitual é em grande parte devido ao próprio Kant, não distinguindo suficientemente entre a exposição e os resultados do processo que conduz a eles. Decerto que não lhe interessa o donde venham as representações elementares - precisamente enquanto não vêm já prontas, constituídas. Todavia, é só por meio do exame de sua produção (o como vêm) que se pode, efetivamente, quer rechaçar a tentação de considerá-las dadas, quer reconhecer a eminência de cada uma, não tanto na sua individualidade, como na perspectiva dos entraves que sua concomitância funcional resolve. Nessa hora, a importância que o presente capítulo alcança não se deve mais à Schematismuslehre como tal, mas sim ao fato de ele tomar-se o desaguadouro de certos problemas.

$E$ É fato que ambas as versões da dedução transitam pela problemática do esquematismo - embora pareça que a segunda o faça mais, com a direta nomeação de uma "síntese figurada" ou speciosa. ${ }^{20}$ Essa comunidade, talvez profunda e de resultados, implicaria a dispensabilidade da Schematismuslehre em razão da completude da dedução? O fato de Kant explicitamente indicar uma "synthesis speciosa" ou "figurada" como atribuição de um entendimento imaginativo-transcendental só faz, por um lado, ampliar a importância do esquematismo (como tratamento pormenorizado das funções daquela, embora não mais inédito), ainda que, por outro, antecipe e prejudique sua compreensão (pela impossibilidade já tacitamente posta de explicar um entendimento assim).

Através da primeira edição da Crítica, o esquematismo poderia ser visto como o coroamento da etapa "subjetiva" da dedução transcendental. Tratar-se-ia de um mesmo plano situando o enfoque de ambos, ou seja, o psicológico. Mas, em 1787, "Kant étudie... le genre et non les spèces de la synthèse, de crainte de retomber dans ses analyses psychologiques antérieures" (Vleeschauwer, 1976, v.III, p.86). O "gênero" e não as "espécies"? Verdade que Kant, propriamente, não "estuda" mais as mesmas espécies de síntese, nem elas próprias permanecem tais e quais. Não há mais uma síntese a priori da "apreensão" (Kant, KrV., A, p.99-100), que é agora somente empírica

20 Kaulbach, 1960, p.126, nota 56, na qual a synthesis speciosa é vista como a "contrapartida" (Gegenstück) da analysis speciosa de Leibniz. Afirma ainda Kaulbach, 1960, p.126: "Por sintese figurada entende-se a ação pela qual e na qual uma figura espacial perfaz-se (vollendet wird) em sua unidade". 
(cf. Idem, B, p.160, 162, nota), bem como a da "reprodução", sobrevivendo, às vezes ambiguamente, na forma de "imaginação reprodutiva", restando apenas a da "recognição", doravante um emblema das mudanças executadas. Todavia, em 1787 continua havendo três sínteses a distinguir: 1. a "figurada" (figürlich / synthesis speciosa), 2. a que "seria pensada na mera categoria e chama-se ligação intelectual (Verstandesverbindung) (synthesis intellectualis)" (Idem, B, p.151) e 3. a síntese que "está sujeita unicamente a leis empíricas, a saber, as da associação" (Idem, B, p.152). A "síntese figurada" é a que se dirige "meramente à unidade sintético-originária da apercepção, isto é, a esta unidade transcendental que é pensada nas categorias", devendo portanto ser chamada de "síntese transcendental da imaginação" (Idem, B, p.151). Justamente ela é vinculada ao esquema: "... como a síntese da última ["da imaginação"] não tem em vista uma intuição singular, mas unicamente a unidade na determinação da sensibilidade, então o esquema é distinto da imagem" (Idem, A, p.140, B, p.179). ${ }^{21}$ Ao contrário, se "a imaginação... deve levar o múltiplo da intuição a uma imagem" (Idem, A, p.120), trata-se aí da simples reprodução de "uma intuição empírica antes havida" (Kant, Ak., v.VII, p.167, 1.25), portanto, do "acolher" (aufnehmen) e "percorrer" (durchgehen) de uma multiplicidade dada, conseqüentemente, de uma imaginação empírica. A "síntese figurada" pode ser dita imediatamente ligada ao esquema, a "intelectual" à categoria isolada, a "empírica" ao objeto psicologicamente tomado; ou, se se quiser: a "figurada" à regra de configuração do múltiplo a prioni, a "intelectual" à regra de ligação do mesmo, a "empírica" à regra de associação do múltiplo empírico.

Nessa nova tripartição da síntese, há que primeiro notar o fato de a "figurada" e a "intelectual" serem prontamente nomeadas de transcendentais: beide sind transzendental, "não meramente porque elas próprias precedem a priori, mas também porque fundam a prion a possibilidade de outro conhecimento" (Kant, KrV., B, p.151). Mas se isso as distancia da "empírica", registre-se também que tanto a "figurada" como a "empírica" (e somente elas) operam com a "imaginação": a "figurada" com a "pura", a "empírica" com a "reprodutiva". A incongruência entre ambas só será plenamente esclarecida quando soubermos que a imaginação pura produz o esquema, a empírica a imagem - isto é: no capítulo do esquematismo.

Mas donde viria então o suposto caráter psicológico da Schematismuslehre? Do fato que a imaginação é a produtora do esquema? "Carente de imagens (der Bilder bedürftigen)", nosso "intellectus ectypus" (Kant, Ak., v.V, p.408, 1.21) não exigiria ele próprio essa dimensão - psicológica?

"Pensamentos sem conteúdo são vazios, intuições sem conceitos são cegas. É, pois, necessário, tanto tornar sensíveis seus conceitos [os conceitos do 'objeto'] (isto é: juntar-lhes o objeto na intuição), quanto inteligíveis suas intuições (as intuições do

21 Essa mesma referência da imaginação à unidade na sintese do múltiplo encontra-se também na primeira versão da dedução; cf. Kant, KrV., A, p.118; 123. 
'objeto'] (isto é: pô-las sob conceitos)" (Kant, KrV., A, p.51, B, p.75). Tal é o prenúncio inaugural do esquematismo como Versinnlichung dos conceitos. Esse prenúncio ocorre, em ambas as edições, precisamente na segunda página da "Introdução" à "lógica transcendental", em que se trata da "idéia de uma lógica transcendental" ("I. Da lógica em geral"). Os dois primeiros parágrafos dessa primeira parte da "Introdução" dizem respeito apenas à (futura) "lógica transcendental", nada tendo a ver com a chamada "lógica geral" ou mesmo com a Logik überhaupt. Os seus seis parágrafos restantes analisam a diferença entre uma "lógica do uso geral" e outra do "uso particular" do entendimento (Idem, A, p.52, B, p.76) ou "lógica geral", "aplicada" (Idem, A, p.53, B, p.77). Esta é assim nomeada "quando se dirige às regras do uso do entendimento sob as condições subjetivas empíricas que a psicologia nos ensina. Tem portanto princípios empíricos, embora seja geral na medida em que se dirige ao uso do entendimento sem distinção de objetos"(Idem, ibid.). Trata-se de "um catártico do entendimento comum" (Idem, A, p.53, B, p.78), noção diretamente ligada a "condições empíricas" (Idem, A, p.52, B, p.77), enquanto o esquematismo refere-se apenas a uma "condição sensível" (Idem, A, p.136, B, p.175). É certo ainda que se tentou aperfeiçoar a "lógica", incorporando-lhe capítulos de natureza psicológica (relativos às "diferentes capacidades de conhecimento" - dentre as quais a "imaginação"), metafísica (em que, por exemplo, se discutia "sobre a origem do conhecimento") ou antropológica (Idem, B, p.VIII) - o que só atesta o "desconhecimento da natureza peculiar dessa ciência" (Idem, ibid.).

Por outro lado, é fato que a Psicologia da época levava em conta questões parcialmente afins à doutrina do esquematismo:

Como, em geral, nasce a referência de uma imagem ao objeto imaginado, e como o pensamento é ligado com a imagem que está diante de nós, de modo que temos a própria coisa na imagem diante de nós? Como a atenção à própria coisa é dirigida para a imagem, de modo que pensamos e refletimos, tal como se tivéssemos a coisa diante de nós? - ou, numa palavia: de que maneira vemos e reconhecemos a coisa na imagem? (Tetens, 1970, t.I, p.83)

Todavia, a Schematismuslehre, por coerência com a noção de uma "lógica transcendental", isto é, que deve não só operar com princípios exclusivamente a prion, mas sobretudo fundar a possibilidade de conhecimentos sintéticos puros, ela não pode, quer conter um só elemento de natureza empírica, quer, gratuitamente, apresentar-se a título de suplementação psicológica de uma erkenntnistheoretische Frage. Se ela o faz, e, com propósito fundado, tal se deve, não tanto já a uma dimensão psicológica do entendimento humano, quanto, antes, à sua índole forçosamente ectípica, isto é, ao fato de todas as suas concepções vincularem-se a um objeto dado (dado primeiro no espaço), e cuja forma de reconhecimento é sua "exposição" (Darstellung) derivativa.

Mas, se a categoria não pode ser levada a imagem alguma (Kant, KrV, A, p.142, B, p.181), sendo no entanto a fonte da "determinação transcendental do tempo", este, 
ou seja, o próprio "tempo", ele é que deverá ser configurado, vale dizer, o "múltiplo" que aí se encontra.

"Não podemos pensar linha alguma sem a traçar em pensamento, círculo algum sem o descrever ..." (Idem, B, p.154); "Não posso representar-me linha alguma, por pequena que seja, sem a traçar em pensamento ..." (Idem, A, p.162, B, p.203); "Que o tempo é expresso através de uma linha (que porém é um espaço), e o espaço através de um tempo (do passar de um período), [tal] é um esquematismo dos conceitos do entendimento. Compositio" (Kant, Ak., v.XVIII, n.6359, p.687, 1. 25-27).

Ora, falar de um não-poder-pensar-exceto-traçando é, à primeira vista, compor uma noção ambígua de intelecto. Mas, a rigor, não se trata de um pensar-traçando, mas de um traçar-em-pensamento. Assim, para salvaguardar a binariedade genética do conhecimento (parte sensível, parte intelectual) é preciso, não um entendimento que, pensando configure, mas um intermediário conceitualmente autônomo que viabilize essa exigência.

Eis o pano de fundo da comparação lançada por Kant no capítulo do esquematismo: “... se eu só penso um número em geral ... esse pensamento é mais a representação de um método ... do que esta própria imagem [ a 'imagem do número cinco' ou de 'uma quantidade (por exemplo: mil)'] ..." (Kant, KrV, A, p.140, B, p.179). Da mesma forma: "O esquema do triângulo não pode existir em nenhum outro lugar, exceto no pensamento ..." (Idem, A, p.141, B, p.180).

A limitação do intelecto ectípico, sua inevitável dependência da imagem, a impossibilidade de auto-representação das Gedanken- e Anschauungsformen, umas e outras entre si se imiscuindo, tal é o quadro fixando os contornos do entendimento humano, resultado de uma crítica da razão pura. Trata-se da própria explicação (não porém da derradeira Grundlegung) de um conhecimento duplamente gerado, ou do fato que possibilita a compreensão histórica do criticismo, enquanto sua natureza é em parte empírico-cética, em parte intelecto-dogmática.

Há mais, porém: o tempo-expresso-pelo-espaço-expresso-pelo-tempo... - essa imbricação originária ist ein Schematism der Verstandesbegniffe; conseqüentemente: “... o tempo, em si [próprio], não pode determinar [a alma] sem representação espacial, e o produto na mesma através da imaginação" (Kant, Ak., v.XVIII, n.6319, p.633, 1.19-20). Creio tratar-se aqui da "imaginação empírica", que opera com imagens (levando o múltiplo a elas, no caso o do sentido interno), pois do contrário a afirmação seria incompreensível e mesmo contraditória diante da Schematismuslehre. Assim, se, de um lado, sozinho, o tempo (ou, melhor: sua "determinação transcendental") não determina ainda o múltiplo interno, para isso carecendo do espaço, de outro, não o faz por meio da "imaginação empírica", que, porém, enquanto configura ọpera diretamente no espaço; pois, se se trata de uma "determinação transcendental", ela não pode, por si própria, levar a uma imagem o "produto" dessa determinação, sendo a mera regra de síntese para um múltiplo figurável. 
Mas de que "produto" se trata? O tempo é a forma pela qual o múltiplo (a prion) é dado à consciência unificadora. Que esta o determine, ou seja, o múltiplo puro temporalmente receptado, tal é o que não pode ser feito na ausência do espaço, forma de recepção do fenômeno externo, por onde o que me afeta é de pronto representado. Justo pelo fato de que o tempo (com o múltiplo nele contido) só pode ser expresso por meio do espaço, tem-se então, de um lado, cumprida a exigência de uma imagem para as representações, e, de outro, garantida sua realidade objetiva.

Tendo de traçar em pensamento, tenho ainda de determinar espacialmente o próprio tempo, e, com ele, o múltiplo a priori. Com isso, o "produto" da determinação do múltiplo interno é, por fim, a própria "imagem" do objeto afetante - que tanto deve estar no "intelecto" (o traçar-em-pensamento), quanto na "sensibilidade" (a representação espacial da Zeitbestimmung). Todavia, é o próprio traçar-em-pensamento que de início requer uma composição entre o sinnlich e o verständlich: a "imagem" apenas decorre como o fato desse "composto" originário, vale dizer, entendimento e imaginação.

Se o "esquema é... distinto da imagem" (Kant, KrV., A, p.140, B, p.179), o do número será o pensamento de "um número em geral" (Idem, ibid.). Da mesma forma, quer "o esquema do triângulo", quer o de um conceito empírico (por exemplo: o do "conceito de cão").

Mas como pensar, traçando-em-pensamento, um "número", um "triângulo", um "cão" - überhaupt?

Não é possível, por exemplo, pensar o cão em geral, sem o concomitante tracejamento regulador. Mas que seja impossível a figura de um cão assim, sobre isso não há que falar, pois não se trata de chegar a uma tal imagem, mas apenas à forma de sua regulação. Tampouco um cão seria como qualquer triângulo, no singular exprimindo o universal, não podendo haver um mesmo tipo de esquema para 0 conceito de cão, como para o conceito de triângulo.

O esquema é então, por fim, o responsável pela execução do processo de identificação do conteúdo fenomênico. Ele é sempre uma determinação de tempo, devendo ser transcrita espacialmente. Essa determinação dá-se sob a forma de unidades (contínuas) acrescidas umas às outras. Mas a completa espacialização desse "acréscimo" (Hinzutuung), a representação de sua figura, tal é o que depende, além da "determinação transcendental do tempo" ou do "acréscimo" de unidades, da determinação empírica do espaço, isto é, da recepção do fenômeno externo, e, em particular, da figura que por ele parcialmente se insinua.

Há, pois, uma regra transcendental, cujo exercício leva à determinação do tempo, como sua inevitável exposição ao tracejamento de figuras no espaço. A figura traçada é assim o resultado da reunião de uma regra transcendental de determinação (cujo exercício produz o tempo, cuja exposição, o espaço) com a afecção externa impressa neste último. Se o esquema carece da fusão entre o sensível e o intelectual, 
isso significa que ele próprio se articula como intelecto-imaginativo, à medida que a "determinação transcendental" é já o movimento produtor do tempo e do espaço.

Que é então o esquema: "termo médio" da "lógica transcendental", elemento de natureza psicológica, mero artifício arquitetônico, apenas repetindo o que afirmara antes a dedução? Partindo do conceito para desembocar na imagem, qual a função cumprida por ele? - ou, talvez: da imagem ao conceito, que intermediário é este? "Aplicação" ou "subsunção"?

Curtius fazia, em 1914, a distinção entre Subsumtionsschematismus e Synthesisschematismus, tendo indicado "que o esquematismo é primeiro (falsamente) determinado como mero esquematismo-da-subsunção, depois (corretamente) como esquematismo-da-síntese" (Lehmann, 1969, p.189). Da mesma forma, Pippin assinala:

It soon becomes evident that Kant's 'One-Many' problem is not 'by virtue of what are many subsumed under one', but how one rule can determine a manifold to produce the unity that makes speaking of 'many under one possible'. ... a concept is a universal as a rule for synthesis, not as a genus or universal type. Hence, the question of subsumtion, the question of the schematism, must be how a sensible manifold can be conceptually determined; not how instances can be recognized as having some common predicate. (Pippin, 1976, p.159)

O caráter regulador do esquema decorre assim do próprio caráter regulador do conceito, ambos de sua parte acordes com a qualidade básica do entendimento humano: a função de unificar a multiplicidade informe mediante regras de síntese. Enquanto o conceito possui a mera regra intelectual de unificação, o esquema fornece-lhe a regra de composição que o orienta no sensivel. Embora Kant afirme que a "filosofia transcendental", "além da regra ... que é dada no conceito puro do entendimento, pode ao mesmo tempo indicar a priori o caso ao qual ela deve ser aplicada" (Kant, KrV., A, p.135, B, p.174-5), o que se dá "em caracteres gerais mas suficientes" (in allgemeinen aber hinreichenden Kennzeichen) (Idem, A, p.136, B, p.175), isso não nos deve fazer pensar que tal ocorra exatamente assim. Não há um "caso" a subsumir-se à categoria, como quaisquer "caracteres" ou esquemas a priori capazes de uma tal operação.

Mas, dir-se-á: que tem a ver "caso" com tracejamento, lógica com Psicologia?... A resposta é simples. Para concluir que um objeto $A$ subsume-se ao conceito $B$, preciso antes ver o objeto, antes ainda o conceito. Todavia, é impossível, nele próprio, ver o conceito. Mas, então, como saber que objeto e conceito se acordam? Não vendo o conceito, não vejo o objeto. Se não há fenômeno sem algo que apareça, tampouco o visto sem o-que-vê.

A identidade de sujeito e objeto, lógica ou psicológica, como "caso" ou "apercepção", "imagem" ou "sentido interno" é fruto de um mesmo processo cognitivo, em que categoria e esquema compõem a regra de uma síntese figurada permitindo ao sujeito a visão do múltiplo unificado. Que tal mecanismo, portanto, detenha um componente psicológico (a "imagem"), tal é o que decorre da limitação 
do intelecto humano. Nem por isso o esquema poderá ser confundido com uma suposta imagem universal - como, por exemplo, pensaria Beth:

le triangle de Kant ne doit pas avoir de déterminations individuelles qui ne découlent pas des conditions générales de sa construction. Si cela voulait seulement dire que, par exemplo, le triangle est sans épaisseur ou même dépourvue de toute couleur, il ne s'agirait que de l'attribution, à l'imagination, d'un très grand pouvoir d'idéalisation, ce qui serait à la nigueur admissible. Mais il est clair que Kant pose à notre imagination des exigences beaucoup plus lourdes encore; il postule la faculté d'imaginer un triangle qui n'est ni scalène, ni rectangle, etc., ce qui est incompatible avec des faits psychologiques élémentaires. (Beth \& Piaget, 1961, p.13)

A Schematismuslehre, pois, não opera com referenciais psicológicos, mas lógico-transcendentais, ainda que as conseqüências da doutrina devam necessariamente levar à elaboração (regulada) das imagens.

Todavia, ela parece adotar uma perspectiva estranha diante da dedução, vale dizer, ante o problema da legitimidade no uso das categorias.

Tratar-se-á, porém, de estranheza aparente, ainda que enganadora. Com efeito, o resultado positivo da dedução afirma a impossibilidade de o conhecimento realizarse sem a interferência da Verbindung, reunindo o múltiplo caoticamente dado (Kant, $\mathrm{KrV}$., B, p.129-30). Já o esquematismo - que em relação às categorias é "a chave de seu uso" (Idem, A, p.181, B, p.224) - apresenta uma doutrina regulando a conformidade das imagens aos respectivos conceitos dos objetos que elas representam. As imagens de todos os triângulos possíveis serão forçosamente adequadas ao esquema do conceito de triângulo. Da mesma forma, quaisquer imagens de um número ou de um objeto empírico, todas se conformando aos esquemas de seus conceitos. Mas, "em contrapartida", o esquema de uma categoria "é algo que não pode ser levado a imagem alguma" (Idem, A, p.142, B, p.181). ${ }^{22}$ Ora, que "algo" é esse? E por que "em contrapartida"? Por acaso os esquemas para os conceitos sensíveis e empíricos poderiam ser levados a imagens? Compreendido literalmente, ou talvez apenas à primeira leitura, o oposto dessa "contrapartida" desemboca em contradição. Pode-se no entanto pensar que os esquemas dos conceitos sensíveis e empíicos apenas regulam a composição das imagens dos objetos pertinentes a esses conceitos, o que não ocorre no caso das categorias, pois, estritamente falando, elas não têm um objeto, cuja imagem pudesse ser regulada. O que então será regulado pelos esquemas dos conceitos puros? Eles são, numa palavra, a mera representação do entendimento como imaginação transcendental, vale dizer, como a regra de unificação para sínteses figuráveis, cuja efetivação depende ainda da ocorrência das afecções. O que, portanto, os esquemas das categorias regulam é, em última instância, a própria possibilidade da experiência.

22 Cf. Heidegger, 1953, p.155-9. Já acerca das críticas de Cassirer envolvendo a leitura que Heidegger fez de Kant, cf. Declève, 1969, p.517-45. 
Viria então a Schematismuslehre ao encontro do problema de uma eventual abstratividade dos conceitos puros? Se em parte sim, ela não surge propriamente em virtude disso, mas devido à questão da "realidade objetiva" das categorias como funções de unificação próprias de um intelecto ectípico. Certamente, elas não têm um objeto cuja universalidade devesse representar-se por imagens, justamente porque fundam o campo de toda objetividade possível. Se isso as confronta com a tese das "idéias abstratas", seu caráter de função é suficiente para afastá-las desse quase-fantasma. Mas, e os demais conceitos, sensíveis e empíricos, ambos operando com imagens? Talvez aí - e por uma concepção imagética da repraesentatio (Lebrun, 1989, p.41-61) - o porquê de um exame do esquematismo desses conceitos. Todavia, se Kant está respondendo a Berkeley, nem por isso o faz num terreno psicológico (Philonenko, 1982, p.11-32, especialmente: p.14-20) - fosse assim e a unidade da obra se comprometeria, a Schematismuslehre envolvendo uma questão estranha ou apenas adjacente a ela, mas não sua. Se o exame do esquematismo desses conceitos tem sua razão de ser na tentativa de solucionar o problema de uma eventual abstratividade, dir-se-á que o mesmo se resolve com a elaboração de uma regra harmonizando o conceito (melhor dizendo: seu esquema) e a imagem de seu objeto. De que maneira então, por exemplo, o conceito de triângulo não seria um flatus vocis? A imagem pela qual me represento um triângulo é a imagem de um triângulo em geral? Keineswegs! - diria Kant concordando com Berkeley e Hume: ela resulta da conformação a uma regra de síntese, unicamente pela qual as imagens que me faço de quaisquer triângulos podem a priori acordar-se com seu conceito - com seu conceito esquematizado.

Vê-se portanto que se os próprios conceitos poderiam ser alvo da crítica às "idéias abstratas", à medida que são esquematizados essa possibilidade desaparece. Mas, note-se: tal se dá só por intermédio da elaboração de um campo de referência (sensível, imagético, esquemático) para todos os conceitos, como produto da atividade de um entendimento imaginativo.

Portanto, seja qual for o conceito, ele sempre se fará acompanhar de um esquema permitindo o reconhecimento de sua "realidade objetiva" através da imagem (conceitos sensiveis e empíricos), ou possibilitando a formulação de um meio (intelecto-sensível) (conceitos puros), por onde "determinação transcendental" e "exposição" do múltiplo unificado sejam os pólos da esfera de um conhecimento possível.

Ainda uma vez: a "realidade objetiva" dos conceitos puros, se toda ela enfim se projeta na imagem, nunca é alcançada por eles mesmos, mas somente pelos conceitos sensíveis e empíricos gozando de uma objetividade tornada possível pela ação categórico-esquemática. Por conseguinte, a questão da "realidade objetiva" da categoria, posta a exigência de uma "imagem" que lha garanta, é sempre uma falsa questão.

Com isso, não o esquema da categoria, mas a categoria esquematizada torna-se o próprio emblema da auto-afecção do eu, em resposta à afecção transcendental, bei 
Gelegenheit der Erfahrung. A "experiência possível" está agora definitivamente circunstrita. A resposta do sujeito cognoscente já forneceu o aparato da produção de um conhecimento puro dos objetos da natureza, em todos os níveis por que ele passa. Mas nenhuma das representações elementares puras é em si propriamente autônoma: todas provêm da mesma Selbsttätigkeit. Perante as demais Erkenntnisvorstellungen, ela é o círculo cujo diâmetro permite uma visão mais uniforme do processo, e relativamente ao qual os outros elementos formam círculos concêntricos.

\section{Advertência}

Todas as citações de obras de Kant têm por base a chamada "Edição da Academia" (Akademie-Ausgabe), na seguinte variante: Unveränderter photomeckanischer Abdruck der Textes der von der Preussischen Akademie der Wissenschaften 1902 begonnenen Ausgabe von Kants gesammelten Schniften. Berlin: Walter de Gruyter, 1968. Esta edição compreende os textos dos nove primeiros volumes da edição original da Academia [Erste Abteilung: Kants Werke (Bd. I-IX)], seguidos de dois tomos com as notas que lhes correspondem [Anmerkungen der Bände I-V / Anmerkungen der Bände VI-IX]. Para os textos restantes seguiu-se a edição original da Academia, a partir do décimo volume. Exclusivamente para a Crítica da Razão Pura (KrV) optou-se pela edição de W. Weischedel: Immanuel Kant: Werke in zwölf Bänden. Frankfurt am Main: Suhrkamp, 1974 (Bd. III-IV). Para a Crítica adotou-se o procedimento habitual nas citações: $A$ designando a primeira edição (1781), $B$ a segunda (1787). As citações de textos extraídos da "Edição da Academia" regem-se aqui pelo seguinte padrão: indicação da edição através da abreviatura "Ak.", seguindo-se os números de volume, página e linha (a barra em diagonal "/" assinala mudança de página na numeração de linha). As expressões latinas empregues por Kant e seus intérpretes (a prioni, a posteriori etc.) foram em geral destacadas na tradução, mesmo quando não apareciam assim no original.

MARQUES, U. R. de A. Notes on schematism in Kant's Critique of Pure Reason. Trans/Form/Ação (São Paulo), v.18, p.121-140, 1995.

- ABSTRACT: This article is an introductory approach to the doctrine of the schematism according to the context of its appearance in the Critique of Pure Reason.

- KEYWORDS: Schema; schematism; transcendental schematism; image. 


\section{Referências bibliográficas}

1 BECK, J. S. Erläuternder Auszug aus den critischen Schriften des Hernn Prof. Kant auf Anrathen desselben von M. Jacob Sigismund Beck / Erster Band, welcher die Critik der speculativen und practischen Vernunft enthält. Riga: Johann Friedrich Hartknoch, 1793.

2 BELAVAL, Y. Libres remarques sur le schématisme transcendental. In: L'Héritage de Kant. Mélanges philosophiques offerts au P.M. Regnier. Paris: Beauchesne, 1982.

3 BETH, E. W., PIAGET, J. Épistemologie mathématique et psychologie. Paris: PUF, 1961.

4 COHEN, H. Kommentar zu Immanuel Kants Kritik der reinen Vernunft. Leipzig: Felix Meiner, 1920. In: Immanuel Kant: Sämtliche Werke; Supplement-Band: Vorländer's Kantbiographie; Cohen's Kommentar zur Kritik der reinen Vernunft (X. Band). Herausgegeben von K. Vorländer. Lepzig: Felix Meiner, s.d.

5 DAHLSTROM, D. O. Transzendentale Schemata, Kategorien und Erkenntnisarten. Kant-Studien, v.75, n.1, p.38-54, 1984.

6 DAVAL, R. La métaphysique de Kant. Paris: PUF, 1951.

7 DECLĖVE, H. Heidegger et Cassirer interprètes de Kant. Revue Philosophique de Louvain, v.67, n.96, nov. 1969.

8 DELEUZE, G. Para ler Kant. Trad. S. D. P. Guimarães. Rio de Janeiro: Francisco Alves, 1976.

9 DETEL, W. Zur Funktion des Schematismuskapitels. In: Kants Kritik der reinen Vernunft. Kant-Studien, v.69, n.1, p.17-45, 1978.

10 HEIDEGGER, M. Kant et le problème de la métaphysique. Introduction et traduction par A. de Waelhens et W. Biemel. Paris: Gallimard, 1953.

11 HERDER, J. G. Verstand und Erfahrung - Eine Metåknitik zur Kritik der reinen Vemunft. Lepzig: Johann Friedrich Hartknoch, 1799.

12 KANT, I. Anthropologie in pragmatischer Hinsicht. (VII)*

13

14 Preisschnift über die Fortschnitte der Metaphysik. (XX)

15 Kritik der Urteilskraft. (V) Kritik der reinen Vernunft.

16 Logik. (IX)

17 Nachträge zur Kritik der reinen Vernunft (I. Auflage). (XXIII)

18 Opus postumum. (XXII)

19 _. Prolegomena zu einer ieder künftigen Metaphysik, die als Wissenschaft wird auftreten können. (IV)

20 . Reflexionen zur Logik. (XVI)

21 . Reflexionen zur Metaphysik. (XVIII)

22 . Was heisst: Sich im Denken orientieren? (VIII)

23 KAULBACH, Fr. Die Metaphysik des Raumes bei Leibniz und Kant. In: Kant-Studien Ergänzungshefte. Köln: Kölner Universitäts-Verlag, 1960.

24 Schema, Bild und Modell nach den Voraussetzungen des Kantischen Denkens. In: Studium Generale, v.18, n.7, p.464-79, 1965.

\footnotetext{
* Os algarismos romanos entre parênteses indicam o volume da obra na "Edição da Academia".
} 
25 LEBRUN, G. A noção de "semelhança", de Descartes a Leibniz. In: DASCAL, M. (Org.) Conhecimento, linguagem, ideologia. São Paulo: Perspectiva, Edusp, 1989.

26 LEHMANN, G. Anwendung und Übergang als Systemprobleme der Kantischen Philosophie. In: Beiträge zur Geschichte und Interpretation der Philosophie Kants. Berlin: Walter de Gruyter, 1969.

27 MARTIN, G. (Ed.) Sachindex zu Kants Kritik der reinen Vemunft. Herausgegeben von G. Martin. Bearbeitet von D.-J. Löwisch. Berlin: Walter de Gruyter, 1967.

28 MELLIN, G. S. A. Encyclopädisches Wörterbuch der Kritischen Philosophie. Jena: Friedrich Fromman, 1797-1804. 6v.

29 MOREAU, J. Berkeley et le schématisme. Kant-Studien, v.79, n.3, p.286-92, 1988.

30 PATON, H. J. Kant's metaphysic of experience. London: George Allen \& Unwin, 1970. 2v.

31 PHILONENKO, A. Études kantiennes. Paris: J. Vrin, 1982.

32 L'oeuvre de Kant. Paris: J. Vrin, 1969. 2v.

33 PIPPIN, R. The schematism and empirical concepts. In: Kant-Studien, v.67, n.2, p.156-71, 1976.

34 PRICHARD, H. A. Kant's theory of knowledge. New York: Garland, 1976.

35 ROCCA, C. LA. Schematismus und Anwendung. In: Kant-Studien, v.80, n.2, p.139-54, 1989.

36 ROTENSTREICH, N. Kant's schematism in its context. In: Dialectica, v.10, n.37, p.9-30, 1956.

37 TETENS, J. N. Philosophische Versuche über die Menschliche Natur und ihre Entwicklung in Die philosophischen Werke. Aalen: Georg Olms, 1970. Band I.

38 VLEESCHAUWER, H.-J. de. La déduction transcendentale dans l'oeuvre de Kant. New York: Garland, 1976. 3v.

39 WALSH, W. H. Schematism. In: Kant-Studien, v.49, n.1, p.95-106, 1957-1958.

40 WATSON, J. The philosophy of Kant explained. New York: Garland, 1976.

41 WINTERBOURNE, A. T. Construction and the role of schematism in Kant's philosophy of mathematics. In: Studies in History and Philosophy of Science, v.12, n.1, p.33-46, 1981.

42 WOLFF, R. P. Kant's theory of mental activity. Gloucester: Peter Smith, 1973. 